\title{
Charge-based deep level transient spectroscopy of B-doped and undoped polycrystalline diamond films
}

Kazimierz Paprocki ${ }^{1, *}$ (D) Kazimierz Fabisiak ${ }^{1}$, Robert Bogdanowicz ${ }^{2}$, Łukasz Gołuński ${ }^{2}$, Elżbieta Staryga ${ }^{5}$, Mirosław Szybowicz ${ }^{3}$, Magdalena Kowalska ${ }^{4}$, and Agnieszka Banaszak-Piechowska ${ }^{1}$

${ }^{1}$ Institute of Physics, Kazimierz Wielki University, Powstańców Wielkopolskich 2, 85-090 Bydgoszcz, Poland

${ }^{2}$ Faculty of Electronics, Telecommunications and Informatics, Gdansk University of Technology, 11/12 G. Narutowicza St., 80-233 Gdansk, Poland

${ }^{3}$ Faculty of Technical Physics, Poznan University of Technology, Piotrowo 3, 60-965 Poznan, Poland

${ }^{4}$ Faculty of Chemical Technology and Engineering, University of Technology and Life Sciences, Seminaryjna 3, 85-326 Bydgoszcz, Poland

${ }^{5}$ Institute of Physics, Technical University of Łódź, Wólczańska 219, 93-005 Lodz, Poland

Received: 3 January 2017

Accepted: 18 May 2017

Published online:

25 May 2017

(C) The Author(s) 2017. This article is an open access publication

\begin{abstract}
The undoped and B-doped polycrystalline diamond thin film was synthesized by hot filament chemical vapor deposition and microwave plasma, respectively. The structural characterization was performed by scanning electron microscopy, X-ray diffraction and Raman spectroscopy. The electrical properties of synthesized diamond layer were characterized by dc-conductivity method and charge deep level transient spectroscopy. The B-doped diamond layers show higher $\mathrm{sp}^{2} / \mathrm{sp}^{3}$ ratios in comparison with that of undoped layers what can have an essential influence on the localized density of states associated with shallow hydrogen acceptor states what is reflected in the values of activation energies which reached the values of $38 \mathrm{meV}$ for B-doped and $55 \mathrm{meV}$ for undoped diamond layers, respectively. The existence of deep level traps, as, for example, associated with B-related acceptors, was not observed.
\end{abstract}

\section{Introduction}

Most of the physical properties of CVD diamond layers are very similar to that of natural diamonds and can find applications in many fields of science and technology such as a new material and can even replace the conventional materials used so far [1-3]. As it is well known, "as-grown" CVD diamond films are always hydrogen terminated, which generates, in both undoped and B-doped, diamond layers p-type surface conductivity [4-6]. Due this effect, even undoped diamond layers can be used as electrode material in electrochemistry [7-9]. The role of hydrogen atoms in the diamond layers is investigated for many years and still remains far from full understanding [10, 11]. The hydrogen atoms are associated mainly with $\mathrm{sp}^{2}$ carbon phase at diamond grain boundaries but can be also trapped in the bulk

Address correspondence to E-mail: paprocki@ukw.edu.pl 
at structural defects (lattice defects and dislocations) $[11,12]$. Tang et al. reported that the infrared active hydrogen is bonded also to the bulk diamond carbon atoms. The distribution of hydrogen in the diamond films is not uniform and may depend on preferential orientation of diamond microcrystals in diamond layer [13]. The type of the preferential orientation additionally determines crystalline quality of diamond layers [14].

The main goal of the present work is to study the electrical properties of boron-doped and undoped CVD diamond films. It is also important to show that the electrical conductivity is mainly dependent on H-related acceptor states. Charge-based deep level spectroscopy (QDLTS) used in this work allows to get information about the activation energies and capture cross sections for each uncompensated, electrically active defects in the diamond layers.

\section{Experimental details}

In present work, two techniques were used for polycrystalline diamond layers:

- The B-doped diamond layers were synthesized on (100) n-type silicon substrate by microwave plasma chemical vapor deposition (MP CVD) technique using SEKI Technotron AX5400S system. The process parameters were as follows: Total pressure was kept at 70 mbar and total flow of gases at $303 \mathrm{sccm}, \mathrm{CH}_{4}$ concentration was 1 vol\%, and the boron dopant precursor $\mathrm{B}_{2} \mathrm{H}_{6}$ was set at 0.05 and $0.15 \%$ in the working gas for Ax768-3 and Ax767-3 samples, respectively.

- The undoped diamond film (Dpk18) was synthesized on polished (111) n-type Si using hot filament chemical vapor deposition (HF CVD) technique [15]. As a working gas, the mixture of methanol vapor and hydrogen $(2.75 \%$ in $97.25 \%$, respectively) was used. The synthesis was carried out at a pressure of $40 \mathrm{mbar}$, and total flow working was kept at $100 \mathrm{sccm}$.

It should be mentioned that the MP and HF CVD methods are characterized by similar growth rates of diamonds layers, i.e., the differences in the activation processes in both methods are negligible [16].

In both cases prior to the growth process, substrates were cleaned in ultrasonic bath in acetone and 2-izopropanol for $5 \mathrm{~min}$. Next, the substrates were seeded using spin-coating of nanodiamond slurry as described elsewhere [17].

The diamond film morphology, grain's sizes and film thicknesses have been studied by scanning electron microscope (SEM), JEOL JSM-820 operating at a voltage of $25 \mathrm{kV}$, using $\mathrm{LaB}_{6}$ Denka cathode. $\mathrm{X}$-ray diffraction spectra were recorded by using DRON-4a, $\Theta-2 \Theta$ XRD diffractometer. A Cu K $\alpha$ X-ray tube was operated at a voltage of $32 \mathrm{kV}$ and $12 \mathrm{~mA}$ current. The Raman spectra were recorded at room temperature in back scattering geometry using Renishaw in Via Raman spectrometer with the $488 \mathrm{~nm}$ line from argon laser as excitation source.

Current-voltage characteristics of $\mathrm{Al} /$ diamond/n$\mathrm{Si} / \mathrm{Al}$ heterojunction were measured in the voltage range of -5 to $+5 \mathrm{~V}$ using a voltage generator Elpan EG20 and Keithley 6485 Picoammeter. Measurements were taken for temperatures range from $190 \mathrm{~K}$ to RT (room temperature).

Q-DLTS measurements were taken in temperature range of 260-380 K, using homemade system in a typical configuration. As an excitation source, the laser light $(405 \mathrm{~nm})$ was used. The excitation pulse duration was controlled by Signal Recovery 197 Light Chopper.

\section{Results and discussion}

Figure 1 shows SEM photographs of the undoped (Dpk18) and B-doped (Ax768-3 and Ax767-3) diamond films. Both types of diamond layers show clear crystalline feature having very similar morphologies.

Average values of grain sizes for all layers estimated from the SEM photographs (using software SemAfore v.5.21) and are collected in Table 1. The diamond crystallites of undoped diamond layer are clearly bigger in comparison with that of borondoped layers. This can be understandable because the thickness of Dpk18 layers is much bigger than other diamond layers. From the other hand, it is well known that the heavy boron doping spoils the diamond structure and, in consequence, leads to the decrease in crystallite's sizes [18]. Additionally, the $\mathrm{B}$-doping leads to the essential increase in $\mathrm{sp}^{2}$ carbon phase content in the layers as it is observed by Raman spectroscopy (Fig. 2 and Table 1).

The Raman spectra of the CVD diamond film (Fig. 2), in general, consist of sharp diamond peak 

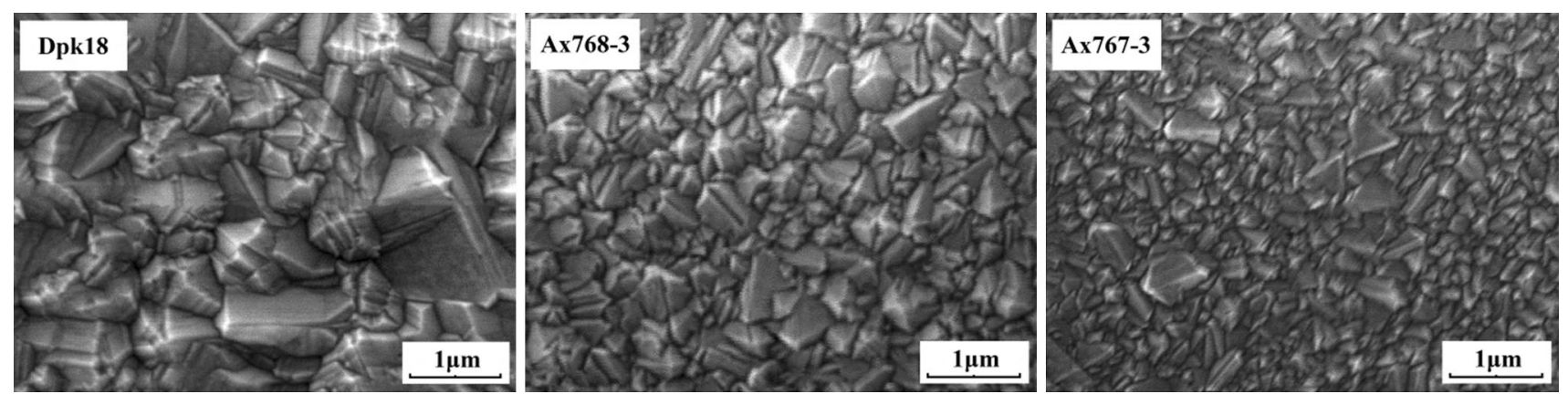

Figure 1 Morphology of obtained diamond films: undoped layer: Dpk18, B-doped layers Ax768-3 and Ax767-3 at the concentration level of $\mathrm{B}_{2} \mathrm{H}_{6}$ in the working gas: 0.05 and $0.15 \%$, respectively.

Table 1 Quality parameters of obtained diamond layers

\begin{tabular}{lllll}
\hline & & Dpk18 & Ax768-3 & Ax767-3 \\
\hline $\mathrm{B}_{2} \mathrm{H}_{6}$ & $\%$ & - & 0.05 & 0.15 \\
Average grain sizes (SEM) & $\mu \mathrm{m}$ & 0.88 & 0.47 & 0.32 \\
The thickness of layers & $\mu \mathrm{m}$ & 7.5 & 2.5 & 2.5 \\
$\mathrm{sp}^{2} / \mathrm{sp}^{3}$ ratio $(f)$ & $\%$ & 1.5 & 2.45 & 2.8 \\
FWHM & $\mathrm{cm}^{-1}$ & 7.9 & 11.2 & 10.7 \\
Slope $(m)$ & $\mathrm{cm}$ & 5.4 & 23 & 28 \\
The hydrogen content $(\mathrm{H})$ & $\%$ & 2.6 & 13.7 & 16.1 \\
Texture coefficient & & & & \\
$\langle 111\rangle$ & $\%$ & 5.1 & 6.0 & 6.9 \\
$\langle 220\rangle$ & $\%$ & 74.6 & 29.5 & 30.8 \\
$\langle 331\rangle$ & $\%$ & 20.3 & 64.5 & 62.3
\end{tabular}

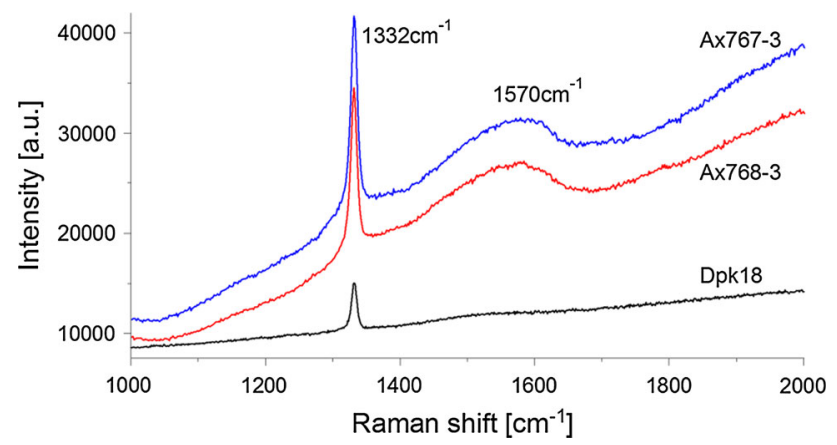

Figure 2 Raman spectra of B-doped (Ax767-3 and Ax768-3) and undoped (Dpk18) diamond layers.

with FWHM in the range of $8-12 \mathrm{~cm}^{-1}$ and broad band, called G-line, peaked at $1570 \mathrm{~cm}^{-1}$ [19].

Additionally each Raman spectrum is characterized by photoluminescence background having different slopes $\mathrm{m}$. The FWHM of diamond Raman line is commonly used as a measure of the diamond quality [19]. The Raman spectrum of the undoped diamond film contains sharp diamond line centered at $1331.9 \mathrm{~cm}^{-1}$ and is characterized by an FWHM having value of about $8 \mathrm{~cm}^{-1}$, which is essentially narrower in comparison with that observed for B-doped diamond layers (Fig. 2 and Table 1). It means that the undoped diamond layers are better quality in comparison with B-doped diamond layers what is in good agreement with morphologies presented in Fig. 1.

The numerical decomposition of the Raman spectra into pure diamond and pure amorphous carbon components allows us to characterize the diamond quality by a method described elsewhere [20]. Results of Raman spectroscopy measurements are collected in Table 1, where $\mathrm{sp}^{2} / \mathrm{sp}^{3}$ is the ratio of nondiamond to pure diamond carbon fracture in the diamond layer.

The diamond Raman peaks in Fig. 2 are superimposed on a broad luminescence background. It is known that broad luminescence background arises from hydrogenated amorphous carbon admixture in diamond layers and its slope $m$ can be used to determine the hydrogen content. The hydrogen content, associated with amorphous carbon at the diamond grain boundaries, can be calculated from the slope $m$ of photoluminescence background of the Raman spectrum (Fig. 2) according to the empirically derived following equation [21]: 


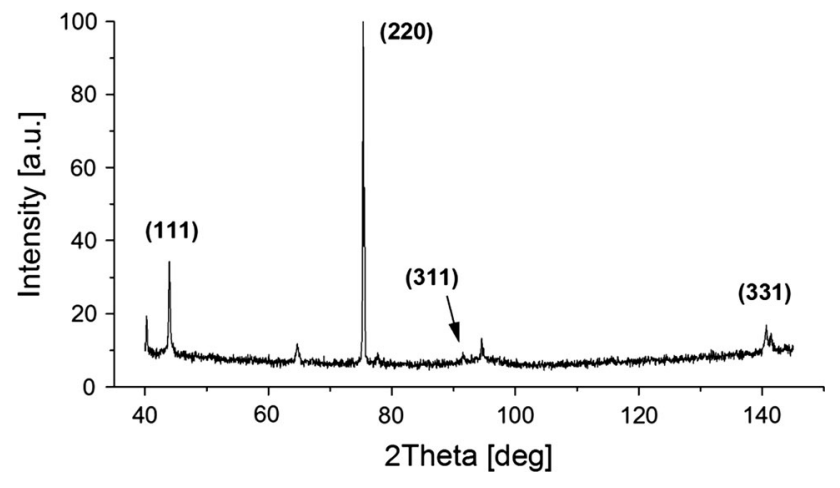

Figure 3 Normalized diffraction spectra of undoped layer Dpk28.

$H[\%]=21.7+16.6 \log \left(\frac{m}{I_{\mathrm{G}}}[\mu m]\right)$

where $I_{\mathrm{G}}$ is integral intensity of Raman G-band.

The slopes $m$ and hydrogen concentrations in amorphous carbon phase admixture, which is small fraction of diamond layers, are collected in Table 1. The $m$ values (Table 1) clearly indicate that hydrogen concentrations in B-doped diamond layers are much higher in B-doped layers what should have an influence on $\mathrm{H}$-related acceptor concentrations in diamond layers.

B-doping not only influences hydrogen concentration but also can be responsible for preferred orientation of diamond microcrystallites which can be estimated from XRD diffraction measurements. Typical XRD spectrum is shown in Fig. 3.

The preferred orientations of crystallites in the layers were estimated using texture coefficient, $T C_{(h k l)}$ $[22,23]$. The results are collected in Table 1.

The texture coefficient (Table 1) for the $\langle 111\rangle$ direction, for all the studied layers is very similar. The differences are observed for other crystalline directions, as, for example, for the undoped layer
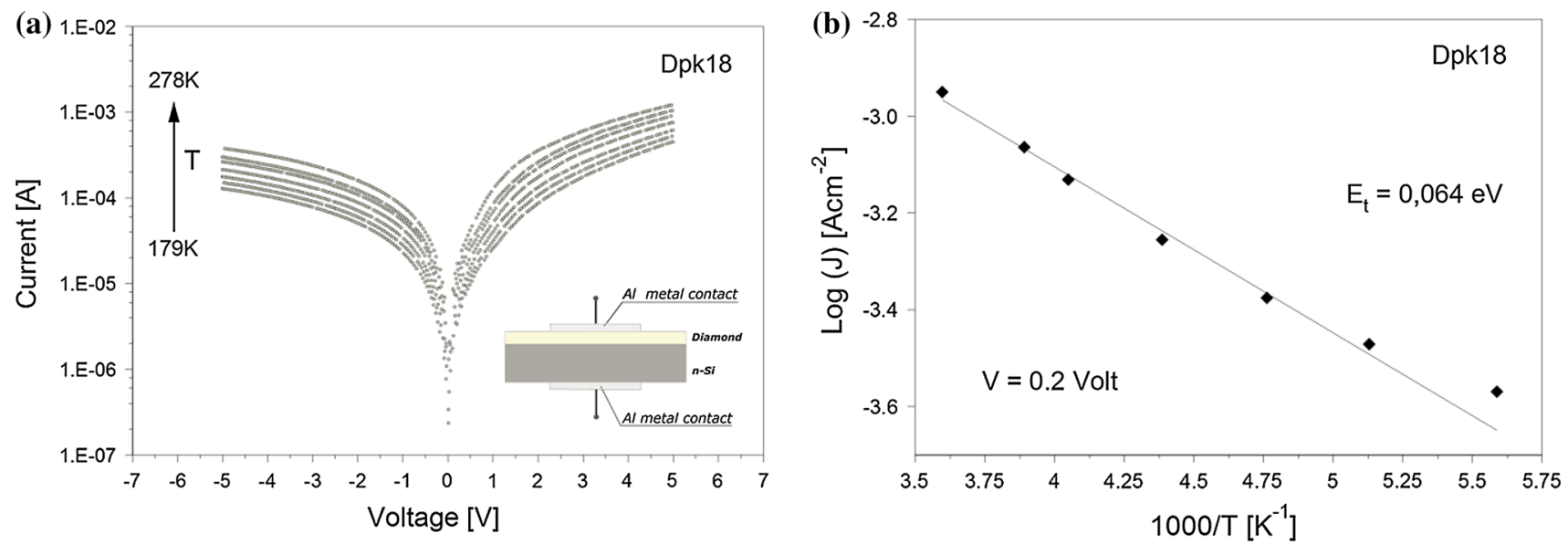

Figure 4 a Semi logarithmic chart I-V-T for sample Dpk18 (the inset shows an electrode configuration), $\mathbf{b}$ the Arrhenius plot.
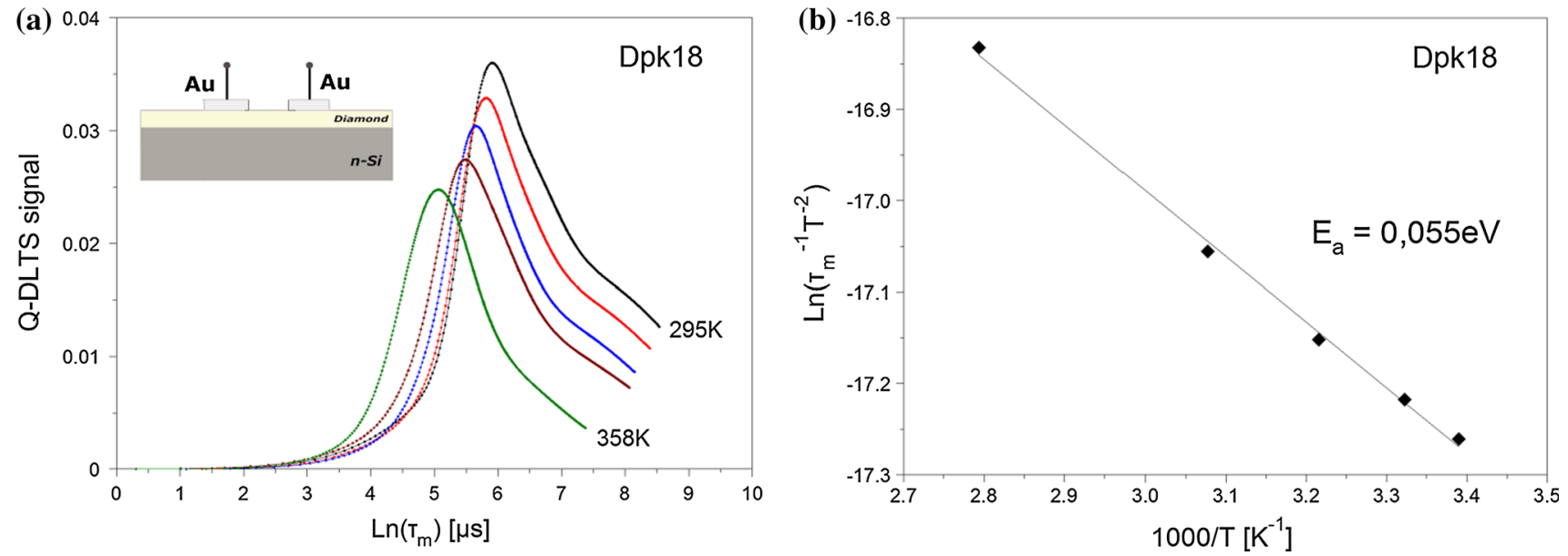

Figure 5 a Q-DLTS spectra for sample Dpk18, b Arrhenius plot for this sample. 

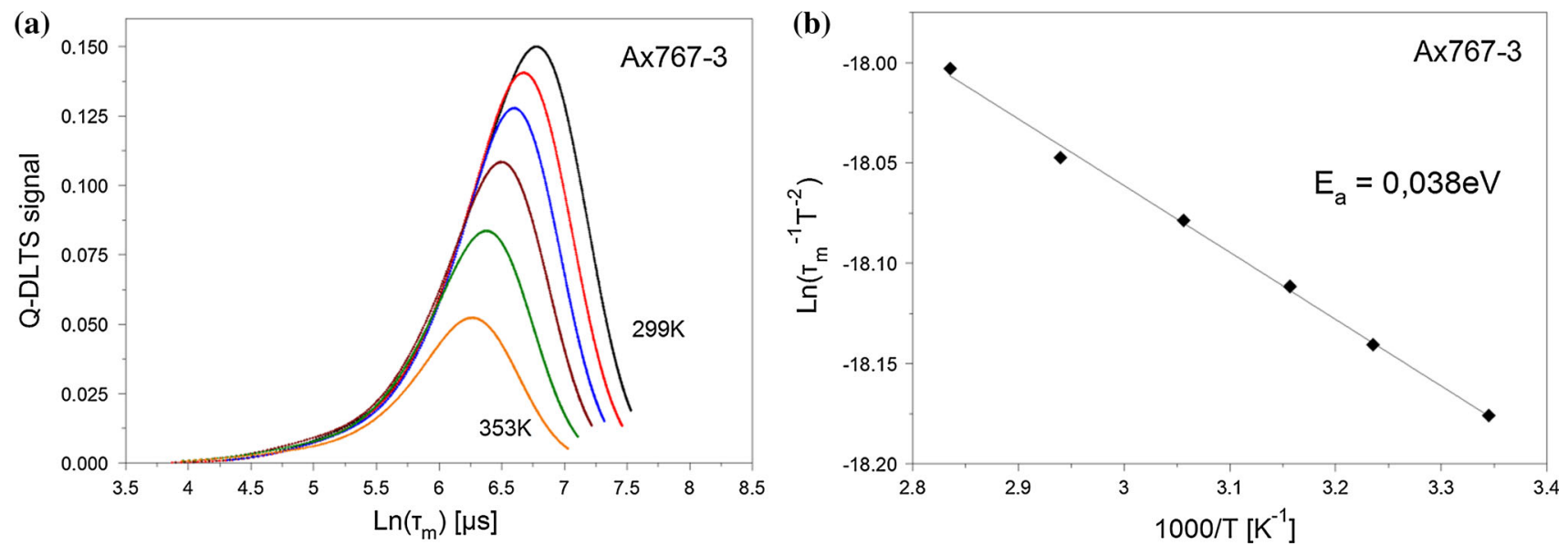

Figure 6 a Q-DLTS spectra for sample Ax767-3, b Arrhenius plot for this sample.

predominate crystallites of $\langle 220\rangle$, and for borondoped layers of $\langle 331\rangle$ orientations.

It is expected that structural properties will govern the electrical properties of diamond layers. Some properties, as, for example, activation energies measured using diamond/n-Si heterojunction, can be determined on the basis of thermionic emission model [24]. But this model does not include the effects of the series resistance of the diamond bulk. If applied bias is higher than barrier height (high forward biases), the nature of the bulk conduction reveals. When the number of injected carriers exceeds the number of thermal carriers (available in the diamond bulk), the charge transport switches from an ohmic character $(\mathrm{I} \sim \mathrm{V})$, to a space-charge-limited current (SCLC) $\left(\mathrm{I} \sim \mathrm{V}^{2}\right)$, described by the Mott-Gurney law $[24,25]$.

Figure 4a shows a I-V-(T) graph for Dpk18, i.e., undoped diamond sample measured in temperatures between ca. $179 \mathrm{~K}$ and RT.

As one can see the heterostructure has slightly straightening properties what confirms earlier reports of the p-type semiconducting nature of the undoped diamond layers $[4,5]$. At low voltages, the conduction mechanism has an ohmic character described by formula (1) [26]:

$J=N_{V} q \mu_{p} \frac{V}{d} \exp \left(-\frac{E_{a}}{k T}\right)$,

where $N_{V}$-valence band density of state $\left(10^{19} \mathrm{~cm}^{-3}\right.$ for diamond), $q$-elementary electric charge, $\mu_{p}$-the mobility of dominant charge carrier, $V$-voltage, $d-$ sample's thickness, $k$-Boltzmann constant.

From the Arrhenius plot, i.e., $\log (\mathrm{J})$ versus $1 / \mathrm{T}$ (Fig. 3b), the activation energy for undoped diamond layer was estimated using formula (2). The obtained activation energy equal to $0.064 \mathrm{eV}$ is rather small and indicates on shallow energy states.

The useful method to study the trapping centers is deep level transient spectroscopy ( $Q$-DLTS) [27]. In this method, the trapped charge transient process is measured by the voltage or light stimulation. The Q-DLTS method used in present work is described in details elsewhere [27-29].

If $t_{1}$ and $t_{2}$ will be the times counted from the beginning and the end of the discharge, then the measured value of the Q-DLTS signal can be write as: $\Delta Q=Q\left(t_{2}\right)-Q\left(t_{1}\right)$. The charge $\Delta Q$ flowed through the circuit during the time period $\Delta t=t_{2}-t_{1}$ is measured as a function of several parameters, including the rate window: $\tau_{m}=\left(t_{2}-t_{1}\right) / \ln \left(t_{2} / t_{1}\right)$.

If the ratio $t_{2} / t_{1}=\alpha$ and will be kept constant, then $\tau_{m}$ will be equal to $\tau_{m}=t_{1}(\alpha-1) / \ln \alpha$, and the maximum of the functional dependence of $\Delta Q\left(\tau_{m}\right)$ can be used to determine the trapping (donor or acceptorlike) center parameters $e_{n, p}$. Taking $\alpha=2$, i.e., $\tau_{m}=t_{1} / \ln 2$, we will have [29]:

$e_{n, p}=\tau_{m}^{-1}=\sigma_{n, p} \Gamma_{n, p} T^{2} \exp \left(-\frac{E_{a}}{k T}\right)$,

where $\Gamma_{n, p}=2 \times \sqrt{3}\left(2 \pi / h^{2}\right)^{3 / 2} k^{2} m_{n,(p)}^{*}, E_{a}$ is activation energy, $\sigma_{n, p}$ is capture cross section, $T$ is the temperature, $k$ is the Boltzmann constant, and $m_{n(p)}^{*}$ is the effective mass of the electron (hole).

The activation energy $E_{a}$ and capture cross section $\sigma_{n, p}$ can be obtained from Arrhenius dependence, i.e., $-\ln \left(\tau_{m}^{-1} \times T^{-2}\right)$ versus $T^{-1}$.

The Q-DLTS spectra registered for Dpk18 and Ax767-3 samples are shown in Figs. 5a and 6a. The 
inset (Fig. 5a) shows an electrode configuration applied for measurements of Q-DLTS spectra.

The results shown in Fig. $4 \mathrm{~b}$ allow to estimate activation energies $E_{a}$ using the Arrhenius plot according to Eq. 3 as it is shown in Fig. $5 b$.

The activation energy determined by Q-DLTS for sample Dpk18 (Fig. 5b) is in a good agreement with the value calculated by the DC measurements (Fig. 4b). Such shallow defects can be associated with chemically bonded hydrogen atoms which create acceptor states just above the top of valence band [30].

The values of activation energies obtained for diamond layers studied within the present work have very similar values. For the sample, Dpk18 amounts to $E_{a}=0.055 \mathrm{eV}$, for Ax768-3 $E_{a}=0.046 \mathrm{eV}$, and for Ax767-3 (Fig. 6) $E_{a}=0.038 \mathrm{eV}$, suggesting a similar origin. For all samples, captured cross section $\sigma_{n, p}$ was approximately $1 \times 10^{-21}-1 \times 10^{-23} \mathrm{~cm}^{2}$, which are characteristic of points defects such as vacancies or dangling bonds [29].

B-related acceptor states have much larger activation energies [31], and their contribution to the electrical properties is not directly observed in measured, in this work, temperature range.

However, as it is seen from Fig. 2 and Table 1 the boron doping has an essential influence on the structural properties of diamond layers and especially on the concentration of $\mathrm{sp}^{2}$ hybridized carbon phase and $\mathrm{H}$-concentration and thus influences the electrical properties of diamond layers.

The highest $\mathrm{sp}^{2} / \mathrm{sp}^{3}$ ratio, the highest chemically bonded hydrogen concentration [4] which leads to higher hydrogen acceptor density of states [32] and can cause the shift of Fermi energy toward the top of valence band. Finally, the activation energies observed for B-doped diamond layers show lower values in comparison with that observed for undoped layer. Both types of layers show similar conductivity character which can be due to the presence of shallow hydrogen acceptor states.

\section{Conclusions}

The diamond layers were synthesized by using two methods: HF CVD method for undoped diamond layers and MP CVD for B-doped layers, respectively. The structural properties including diamond quality, crystallite's sizes and preferential orientations of
B-doped and undoped diamond layers show essential differences both in diamond quality (FWHM Raman band) as in the ratios of $\mathrm{sp}^{2} / \mathrm{sp}^{3}$ and H-concentrations.

The activation energies and captured cross section were estimated on the basis of QDLTS measurements. The activation energies for B-doped are clearly lower $(0.038 \mathrm{eV})$ in comparison with those of estimated for undoped layer $(0.055 \mathrm{eV})$.

These results are in agreement with the results obtained in DC measurements. The obtained results (small activation energies) are characteristic for hydrogenated CVD diamond layers. Within the specified temperatures range, the existence of deep level traps, associated also with B acceptors, was not observed.

\section{Acknowledgements}

This work was supported by the Polish National Science Centre (NCN) under the Grant No. 2014/14/ M/ST5/00715. The DS funds of the Faculty of Electronics, Telecommunications and Informatics of the Gdansk University of Technology are also acknowledged. This work was also partially supported by Grant Etiuda NCN Nr UMO-2014/12/T/ST5/00028.

\section{Compliance with ethical standards}

Conflict of interest The authors declare that they have no conflict of interest.

Open Access This article is distributed under the terms of the Creative Commons Attribution 4.0 International License (http://creativecommons.org/ licenses/by/4.0/), which permits unrestricted use, distribution, and reproduction in any medium, provided you give appropriate credit to the original author(s) and the source, provide a link to the Creative Commons license, and indicate if changes were made.

\section{References}

[1] May PW (2000) Diamond thin films: a 21st-century material. Philos T Roy Soc A 358:473-495. doi:10.1098/rsta.2000. 0542

[2] Bigelow LK, D'Evelyn MP (2002) Role of surface and interface science in chemical vapor deposition diamond 
technology. Surf Sci 500:986-1004. doi:10.1016/S00396028(01)01545-X

[3] Davis RF (1993) Deposition, characterization, and device development in diamond, silicon carbide, and gallium nitride thin films. J Vac Sci Technol A 11:829-837. doi:10.1116/1. 578313

[4] Ballutaud D, Jomard F, Kociniewski T, Rzepka E, Girard H, Saada S (2008) $\mathrm{Sp}^{3} / \mathrm{sp}^{2}$ character of the carbon and hydrogen configuration in micro and nanocrystalline diamond. Diam Relat Mater 17:451-456

[5] Rakha SA, Jianqing C, Huihao X, Guojun Y, Zhu D, Gong J (2009) Incorporation of hydrogen in diamond thin films. Diam Relat Mater 18:1247-1252

[6] Luong JHT, Male KB, Glennon JD (2009) Boron-doped diamond electrode: synthesis, characterization, functionalization and analytical applications. Analyst 134:1965-1979. doi:10.1039/b910206j

[7] Torz-Piotrowska R, Fabisiak K, Paprocki K, Szybowicz M, Staryga E, Banaszak A (2011) Electrochemical properties of undoped CVD diamond films. J Phys Chem Solids 72:1225-1229. doi:10.1016/j.jpcs.2011.07.009

[8] Mosinska L, Fabisiak K, Paprocki K, Kowalska M, Popielarski P, Szybowicz M (2013) Undoped CVD diamond films for electrochemical applications. Electrochim Acta 104:481-486. doi:10.1016/j.electacta.2013.03.111

[9] Mosińska L, Kowalska M, Popielarski P, Fabisiak K, Paprocki K, Szybowicz M, Wrzyszczyński A, Zhusupkalieva GK (2013) Cyclic voltammetry and impedance studies of undoped diamond films. Mater Sci Pol 31:146-150. doi:10. 2478/s13536-012-0081-5

[10] Titus E, Misra DS, Sikder AK, Tyagi PK, Singh MK, Misra A, Ali N, Cabral G, Neto VF, Gracio J (2005) Quantitative analysis of hydrogen in chemical vapor deposited diamond films. Diam Relat Mater 14:476-481. doi:10.1016/j.dia mond.2004.12.001

[11] Maclear RD, Butler JE, Connell SH, Doyle BP, Machi IZ, Rebuli DB, Sellschop JPF, Sideras-Haddad E (1999) The distribution of hydrogen in polycrystalline CVD diamond. Diam Relat Mater 8:1615-1620. doi:10.1016/S09259635(99)00061-8

[12] Reichart P, Datzmann G, Hauptner A, Hertenberger R, Wild C, Dollinger G (2004) Three-dimensional hydrogen microscopy in diamond. Science 306:1537-1540

[13] Tang CJ, Neves AJ, Neto MA, Fernandes AJS (2004) Investigation of hydrogen incorporation in CVD diamond films using infrared reflection spectroscopy. Diam Relat Mater 13:769-775. doi:10.1016/j.diamond.2003.10. 074

[14] Sails SR, Gardiner DJ, Bowden M, Savage J, Haq S (1994) Stress and crystallinity in $<100><110>$ and $<111>$ oriented diamond films studied using Raman microscopy. Appl Phys Lett 65:43-45. doi:10.1063/1.113067

[15] Fabisiak K, Torz-Piotrowska R, Staryga E, Szybowicz M, Paprocki K, Banaszak A, Popielarski P (2012) The influence of working gas on CVD diamond quality. Mater Sci Eng B 177:1352-1357. doi:10.1016/j.mseb.2011.12.013

[16] Bachmann PK, van Enckevort W (1992) Diamond deposition technologies. Diam Relat Mater 1:1021-1034

[17] Bogdanowicz R, Sobaszek M, Ryl J, Gnyba M, Ficek M, Gołuński Ł, Bock WJ, Śmietana M, Darowicki K (2015) Improved surface coverage of an optical fibre with nanocrystalline diamond by the application of dip-coating seeding. Diam Relat Mater 55:52-63. doi:10.1016/j.dia mond.2015.03.007

[18] Wei J, Li CM, Gao X, Hei L, Lvun F (2012) The influence of boron doping level on quality and stability of diamond film on Ti substrate. Appl Surf Sci 258:6909-6913

[19] Fabisiak K, Banaszak A, Kaczmarski M, Kozanecki M (2006) Structural characterization of CVD diamond films using Raman and ESR spectroscopy methods. Opt Mater 28:106-110. doi:10.1016/j.optmat.2004.11.057

[20] McNamara KM, Gleason KK, Vestyck DJ, Butler JE (1992) Evaluation of diamond films by nuclear magnetic resonance and Raman spectroscopy. Diam Relat Mater 1:1145-1155. doi:10.1016/0925-9635(92)90088-6

[21] Casiraghi C, Piazza F, Ferrari A, Grambole D, Robertson J (2005) Bonding in hydrogenated diamond-like carbon by Raman spectroscopy. Diam Relat Mater 14:1098-1102

[22] Rusu DI, Rusu GG, Luca D (2011) Structural characteristics and optical properties of thermally oxidized zinc films. Acta Phys Pol A 119:850-856

[23] Kuo CT, Lin CR, Lien HM (1996) Origins of the residual stress in CVD diamond films. Thin Solid Films 290-291:254-259. doi:10.1016/S0040-6090(96)09016-5

[24] Madaleno JC, Cabral G, Titus E, Pereira L, Grácio J, Ali N (2006) Comparative study of the electrical properties of diamond films grown by microwave plasma assisted and hotfilament chemical vapor deposition. Thin Solid Films 515:106-112. doi:10.1016/j.tsf.2005.12.049

[25] El-Nahass MM, Abd El-Rahman KF (2007) Investigation of electrical conductivity in Schottky-barrier devices based on nickel phthalocyanine thin films. J Alloys Compd 430:194-199. doi:10.1016/j.jallcom.2006.04.056

[26] El-Nahass MM, Metwally HS, El-Sayed HEA, Hassanien AM (2014) Electrical conduction mechanisms of thermally evaporated 5,10,15, 20-tetraphenyl-21H, 23H-porphine iron (III) chloride thin films. Curr Appl Phys 14:161-165. doi:10. 1016/j.cap.2013.10.020

[27] Polyakov VI, Rukovishnikov AI, Rossukanyi NM, Pereverzev VG, Pimenov SM, Carlisle JA, Gruen DM, Loubnin 
EN (2003) Charge-based deep level transient spectroscopy of undoped and nitrogen-doped ultrananocrystalline diamond films. Diam Relat Mater 12:1776-1782

[28] Barancok D, Kelesi L, Kluvanek P, Vajda J (2004) Related features of TSD and Q-DLTS methods. J Electr Eng 55:232-238

[29] Polyakov VI, Rossukanyi NM, Rukovishnikov AI, Pimenov SM, Karabutov AV, Konov VI (1998) Effects of post-growth treatment and coating with ultrathin metal layers on the band bending and field electron emission of diamond films. J Appl Phys 84:2882-2889
[30] Gaudin O, Whitfield MD, Foord JS, Jackman RB (2001) Deep level transient spectroscopy of CVD diamond: the observation of defect states in hydrogenated films. Diam Relat Mater 10:610-614. doi:10.1016/s0925-9635(00)00418-0

[31] Damianos TK, Gaudin O, Whitfield MD, Jackman RB (2002) Ion implantation of sulphur, boron and nitrogen in diamond: a charge-based deep level transient spectroscopic investigation. Diam Relat Mater 11:342-346. doi:10.1016/ s0925-9635(01)00562-3

[32] Williams OA (2011) Nanocrystalline diamond. Diam Relat Mater 20:621-640 